\title{
Pathways To Policy Impact: A New Approach For Planning And Evidencing Research Impact
}

\author{
Mark S. Reed ${ }^{1 *}$, Rosalind Bryce ${ }^{2}$, K. Ruth M. Machen ${ }^{3}$
}

${ }^{1}$ Centre for Rural Economy and Institute for Agri-Food Research and Innovation, School of Natural and Environmental Sciences, Newcastle University, Newcastle, UK

${ }^{2}$ Centre for Mountain Studies, Perth College, University of the Highlands and Islands

${ }^{3}$ School of Architecture, Planning and Landscape, Newcastle University

\begin{abstract}
Background: The use of research in policy settings is complex, unpredictable and influenced by a range of poorly understood social factors. This makes it difficult to plan for, facilitate and evaluate policy impacts arising from research.

Aims and objectives:

1. Propose and test tools for planning for and facilitating research impact, based on a new logic model combined with a novel approach to public/stakeholder analysis

2. Propose and test methods for establishing causal links between research and policy impacts

3. Use case study findings to provide new empirical insights into the social processes that mediate the generation of impact from research

Methods: Social Network Analysis, qualitative analysis of semi-structured interviews and analysis of secondary data were used in a case study of peatland climate change research in Scottish Government policy.

Findings: Boundary organizations and centrally positioned, well-trusted individuals, were crucial to the development of a trusted body of research in which policy-makers were sufficiently confident as the basis for policy.

Discussion and conclusions: The non-linear social dynamics that characterize sciencepolicy networks can be understood and evaluated. By using the tools described in this paper, researchers and other stakeholders can better plan, facilitate and evaluate research impact.
\end{abstract}

\section{Introduction}

Despite calls for ever more evidence-based policy, the relationship between research evidence and policy is beset with challenges arising from mis-matched ideologies, timelags and attribution (Reed and Meagher, 2018). Evidence is rarely clear-cut or uncontested, and increasingly diverse knowledge claims need to be evaluated as part of the policy-making process (e.g. Sanderson, 2006; Crilly et al., 2010). Decision-makers 
must consider moral and ideological arguments alongside practicalities (such as budget constraints) and unpredictable external events that constantly change the parameters of the decision being made. Factors such as these contribute towards significant time-lags between the production of new evidence and its use in policy. Finally, even if challenges around ideology and timing can be resolved, it is often difficult to attribute policy change to a single research project or finding.

This is a problem because research funders and Governments around the world are increasingly demanding evidence that their investments have contributed towards societal benefits or "impacts" 1 (Reed, 2018). As a consequence, there are now concerns that researchers may be biasing activities towards more instrumental impacts that are easier to quantify and evidence (Meagher and Martin, 2017; Chubb, 2017; Chubb and Reed, 2018). There is therefore an urgent need to develop ways of assessing pathways to policy impacts ${ }^{2}$ that can provide feedback to researchers and policy-makers to enhance impact, whilst also providing reliable evidence when far-reaching and significant impacts occur.

Methods are needed that can evaluate the messy complexity of knowledge flows that occur simultaneously across overlapping peer-to-peer networks, with different actors dynamically facilitating, blocking and/or transforming evidence over time. Viewed in this way, pathways to policy impacts may be conceptualised as a social learning process in which changes in understanding occur as researchers and policy communities influence each other and together learn new concepts, attitudes, capacities and policy options through processes of social interaction (Reed et al., 2010; Cairney and Oliver, 2017). While this conception may be an accurate representation of pathways to policy impacts in theory, in practice it presents a huge methodological challenge. Existing methods do not typically capture knowledge flows between individuals in social networks, and the methods that have been developed to evaluate the contribution of research to impact have not been widely adopted.

This paper addresses these methodological challenges by proposing and testing a new approach to planning and facilitating research impact that is being rapidly adopted across the research community. To do this, we present a rare multi-year analysis of the social dynamics of a science-policy network as it adapted to evolving evidence needs from policy stakeholders in parallel with a rapidly evolving evidence-base. Drawing on a substantive body of qualitative interview data and quantitative social network data, the goals of this analysis are to use a case study of peatland climate change research in Scottish Government policy to:

4. Propose and test tools for researchers and stakeholders to plan for and facilitate research impact, based on a new logic model combined with a novel approach to public/stakeholder analysis

5. Propose and test a novel combination of methods for establishing causal links between research and policy impacts

\footnotetext{
${ }^{1}$ We define research impact as demonstrable benefits to individuals, organisations and society that could not have been possible without new knowledge arising from research

2 We define a policy impact as a course (or principle) of action proposed, adopted and/or implemented by an organisation or nation on the basis (to some extent) of evidence from research
} 
6. Provide new empirical insights into social processes that mediate the generation of impact from research, including the role of social networks, boundary organisations and trust in processes of learning and action in policy networks

The next section proposes new methods for planning and facilitating research impact. We then evaluate how the proposed method was used to plan for and facilitate impact in the case study of Scottish policy on peatlands and climate change. To do this, we propose a novel combination of methods for establishing causal links between research findings and policy impacts, based on Social Network Analysis (SNA) and the qualitative analysis of interviews, combined with secondary data and other evidence in a narrative evaluation or "impact case study". This is one of the most comprehensive empirical studies of a pathway from research to policy impacts that has been published to date. We conclude the paper by discussing internationally relevant findings from the case study that advance our theoretical understanding of how science-policy networks operate. In this way, we provide new methods for the planning, facilitation and evaluation of research impact that can be used across a range of disciplinary and policy context internationally.

\section{A new approach for planning and facilitating research impact}

\section{A new logic model for research impact planning}

Logic models are a family of impact evaluation methods that identify causal processes in cause and effect chains to show the contribution (rather than sole attribution) research makes to impact in the context of wider supporting or mediating factors and contexts (Rush and Ogborne, 1991; Julian, 1997). They include methods such as logical framework analysis or "logframes" (Gasper, 2000) and related "theory of change" approaches (Quinn, 1988). They can simplify the process of both planning for and evaluating pathways to impact. They identify a desired or planned impact, such as a policy (or other) change, and help teams identify steps to reach and evaluate progress towards those impact goals. Although widely used in international development, logic models present three challenges in the context of research impact. Our proposed logic model, the Fast Track Impact Planning Template (Table 1), attempts to overcome these challenges:

1. Logic models are driven by impact goals, which researchers typically struggle to define clearly at the outset. We therefore designed a logic model, the Fast Track Impact Template in Table 1, that users can start populating with either their impact goal (column 1) or their target publics/stakeholders (column 2; for example, organizations that are part of the policy community);

2. For logic models to be used to evaluate research impact, the impact goals and activities must be explicitly linked to research. If not constrained in this way, their use can lead to activities that achieve impacts unrelated to research, which would therefore not constitute "research impact" as defined in the introduction. For this reason, the Fast Track Impact Planning Template (Table 1) identifies the interests of stakeholders and publics explicitly in relation to the research/project, rather than listing their wider interests (column 3). Table 1 also identifies indicators of research impact in column 6 (and successful pathways to impact, column 5) a priori, to help refine the articulation of clearly focused goals in column 1 (and activities in column 4) that will lead to measurable impacts linked to the research; and 
3. Logic models shed little light on the way knowledge arising from research gets into policy through interactions between different policy actors and other stakeholders. We have therefore integrated the logic model approach with methods for systematically identifying publics and stakeholders likely to be interested in (or able to influence or benefit from) different types of research, as described in the next section.

Insert Table 1 here

\section{Prioritising publics and stakeholders for engagement}

"Stakeholder analysis" techniques range from methods to identify and categorise publics and stakeholders to methods capable of analyzing relationships between different public and stakeholder groups (Reed et al., 2009). Stakeholder analysis has traditionally only focused on the relative interest and influence of stakeholders (Freeman, 1984; Donaldson and Preston, 1995; Mitchell et al., 1997). The normative goal of this tool in its original conception was to harness the positive influence of stakeholders to meet the strategic objectives of firms, or to "neutralize" or "defeat" stakeholders who had the power to threaten the firm' s interests (Freeman, 1984: 45). For this reason, many later contributions to this literature from other disciplines (notably applications of the method in the domains of environment and health e.g. Grimble and Chan, 1995; Brugha and Varvasovsky, 2000) turned stakeholder analysis on its head, as a tool to identify and empower stakeholders that had been previously marginalized from decision-making processes. As a result, stakeholder analysis is now used widely as a tool for identifying pathways to impact, including the identification of hard-to-reach groups who might benefit from research (Reed, 2018).

However, traditional interest-influence matrices implicitly equate interest to benefit, despite there being no robust theoretical relationship between these two variables. Indeed, there is ample evidence that not all interested parties will benefit equally from research, with some highly interested parties receiving considerably greater benefit from their engagement with research than other highly interested parties, depending on the nature of their interests (de Vente et al., 2016). Given the pre-occupation of the impact agenda with providing benefit (the ultimate impact), rather than just influence (just one part of the pathway to impact), it is important for stakeholder analysis tools to be able to differentiate between levels of likely benefit, for groups with differing levels of interest in the research. This is particularly salient to public engagement, where the majority of publics have little influence over decisions, but will have considerably different interests, leading to different levels of benefit (Reed et al., 2018). Therefore, instead of using traditional stakeholder analysis tools based on interest and influence, we propose a method for "publics/stakeholder analysis" that is designed to work as effectively for prioritizing publics as it does for stakeholders. The key methodological innovation we propose is to add a third variable to the analysis, so any stakeholder or public can be analysed in relation to their relative interest, influence and/or likely benefit. Although we propose benefit as a variable specifically to help prioritise publics (who may all have low levels of influence), in reality any stakeholder or public may be analysed in relation to both their influence and benefit if both variables provide useful information against which different groups can be prioritized for engagement. Significantly, this new methodological approach enables hard-to-reach publics who could benefit significantly from research (but may have limited influence) to be identified and prioritized as part of a pathway to impact. 
As such, Table 2 builds on the "extendible matrix" approach to stakeholder analysis proposed by Reed and Curzon (2015), to assess the relative influence of stakeholders (to facilitate or block research impact), and to assess the relative benefit likely to be derived from different publics from engaging with the research. This distinction is further explored in Figure 1, which shows how stakeholder analysis and publics analysis can be used to identify stakeholders and publics on the basis of their relative influence or benefit, as well as their relative interest in the research. The publics/stakeholder analysis in Table 2 can used prior to the logic model in Table 1. The most relevant stakeholders and publics (based on their influence and/or likely benefit) and their interests are then used to populate columns 2 and 3 of the logic model.

[insert Tables 1-2 and Figure 1 here]

\section{Methods}

\section{Research design}

To meet our first research goal (see introduction), we tested the two new research impact planning tools proposed in the previous section (Tables 1-2 and Figure 1), using a case study of climate change research in Scottish Government. To do this, we used a mixed methods approach (described below) to evaluate the significance and reach of impacts arising from research on peatlands and climate change in Scotland that used the two new impact planning tools. To meet our second goal, we designed our mixed methods approach to establish causal links between research findings and policy impacts. To do this, we used SNA and qualitative interviews to evaluate the pathways that were used to reach each of the impacts identified under the first goal, establishing cause and effect between research and impacts that arose within the Scottish peatland and climate change policy network. Finally, to meet our third goal, the discussion uses findings from research into the previous two goals to consider the role of social networks, boundary organisations and trust in processes of learning and action in policy networks.

The methods that follow were designed to serve each of these three purposes in parallel, providing an evaluation of impacts arising from the use of new impact planning tools (goal 1), providing evidence of causal links between research and policy impacts (goal 2) and providing empirical evidence that could shed light on social processes of impact generation from research (goal 3).

\section{Methodology}

Table 3 shows the impact plan that was tested. The version published in Table 3 is amended slightly from the original version that was created prior to the research (heading titles have changed to be consistent with Table 2, activity indicators were added during the research process rather than at the outset and the timings given are for the last iteration of the impact plan towards the end of the project). The impact plan was then enacted through a series of linked research projects that sought to understand the dynamics and governance of Greenhouse Gas emissions from UK peat bogs between 2005-2014 (Table 4).

[insert Tables 3 and 4 here] 
The research projects listed in Table 4 worked with members of the Scottish peatland and climate change policy network ${ }^{3}$, concerned with policy on land use and management decisions in Scottish peatlands and the effects of these decisions on climate change. For the purposes of this paper, we consider the peatland and climate change policy network to include politicians, policy analysts, evidence analysts, those implementing policy (in this case, land managers and advisors from Scottish Natural Heritage working in peatlands), and researchers who provide evidence to any of the preceding groups in this list (whether from the Scottish Government's Main Research Providers, such as the James Hutton Institute, or Higher Education Institutes).

The research was conducted in three phases, described in Table 4. A mixed methods approach was adopted to provide a comprehensive and robust evaluation of impacts arising from the use of the new impact planning methods proposed in the previous section (our new logic model, the Fast Track Impact Planning Template, and our new approach to publics/stakeholder analysis). By evaluating impacts arising from the use of new impact planning methods, we seek to provide an evaluation of the utility of these methods for planning and evidencing impact. Our mixed methods evaluation of impacts arising from these tools combined: i) quantitative social network analysis; ii) qualitative analysis of interview transcripts; and iii) narrative impact evaluation methods. We provide insights into the development of the policy network and its use of evidence over a period of five years between 2010-2014, however there was only limited overlap between interviewees from the three phases. A more longitudinal approach, revisiting a higher proportion of the interviewees in each phase may have yielded more insights into the temporal changes that occurred during the evaluation period. The rest of this section details the methods used in each of the three phases in Table 4, and explains how they were developed to meet each of the paper's three research goals.

\section{Phase 1: Social network analysis interviews}

A combination of social network analysis and semi-structured interviews was used to investigate the information pathways between research, policy and implementation for peatlands and climate change in Scotland in 2010-2011. Specifically, we sought to address the following questions: 1) To what extent is the policy network (specifically, politicians, policy analysts, evidence analysts and those implementing policy - in this case, land managers and advisors from government agencies working in peatlands) aware of research related to peatlands and climate change and how consistent are the views of the policy community on relevant research findings? 2) What sources does the policy community use to form their view of research findings relevant to peatlands and climate change? 3) Are there socially mediated barriers to effective exchange of research that can contribute to improved peatland and climate policy?

A stakeholder analysis was conducted (using methods from Reed et al. 2009) to identify key individuals involved in research, policy and management of the Scottish uplands and subsequently 40 individuals took part in interviews or an online survey to collect social

\footnotetext{
${ }^{3}$ We define this "policy network" after Helco (1978) as containing both political actors (who directly contribute towards or make policy decisions) and other actors who move in an out of policy and decision-making arenas with diverse perspectives on policy (who indirectly contribute towards policy decisions). We use this in preference to the narrower conception of a "policy community", in which there is a limited number of participants who share similar policy perspectives with a limited number of political actors who make decisions excluding publics and parliament (after Rhodes, 1988).
} 
network and contextual qualitative data related to research findings relevant to upland Scotland. Stakeholders were asked about the pathways of a research finding that they had recently become aware of. In this paper we consider the data given by those who discussed peatlands and climate change. The social network analysis measures the flow of information at the level of individuals and organisations but also included source information materials as network nodes e.g. articles, key research reports which were produced by an organization or punlished by an academic journal. For example, respondents were asked to name all sources that had contributed to their knowledge of a specific research finding and all of the pathways by which they then passed on the information. This allowed us to consider the relative influence of interpersonal interactions as well as information obtained from sources such as academic journals. We were able to track the pathways of specific research findings and the influence of these pathways on the awareness and understanding of research by key individuals in policy networks. Lewis (2006) has demonstrated the usefulness of SNA for identifying the relative strengths of different actors in influencing knowledge flows within networks pointing to the importance of personal, positional and social ties in shaping levels of influence that do not always follow hierarchical rules. Following Valente and Pumpaung's (2007) recommendation for a mixed methods approach to identifying influential actors, we conducted interviews that combined an evaluation of SNA ties (identity of information sources, dissemination targets, frequency of communication along each pathway), with more qualitative questions about relationships within the networks and perceptions of barriers to the use of research in policy. This indicated the extent to which aims and views were held in common and what level of trust existed between individuals and organizations. General perspectives on challenges and approaches to evidence based policy were also revealed. Our goal was to better understand factors affecting the influence and impact of certain information on different stakeholders. We also sought to assess the importance of who produced the information or research, and who supported or promoted it within the policy network. Qualitative segments of interviews were recorded and transcribed, and analysed using Grounded Theory Analysis (Strauss and Corbin, 1994).

\section{Phase 2: In-depth qualitative interviews}

A total of 41 semi-structured interviews were conducted with research scientists, boundary actors and Scottish Government civil servants between 2012-14 to explore practices of knowledge translation for policy audiences. Interviews lasted an hour and were recorded, transcribed and coded with NVIVO software, using an emic approach. Whilst less instrumentally focused on impact per se, these in-depth interviews sought to further understand the processes of knowledge circulation, and the opportunities and constraints faced when working at the science-policy boundary in Scotland. In doing so they offer further insights into the opportunities and possibilities for attaining research impact.

\section{Phase 3: Narrative impact evaluation}

The narrative impact evaluation drew on secondary data to triangulate and extend findings from the first two empirical data collection phases. This evaluation was guided by the indicators identified a priori as part of the impact plan (columns 5 and 6 of Table 3 ). Additional data was collected via keyword searches of policy documents and key informant interviews with prominent figures in the policy community who had been 
involved in the pathway to impact, which helped identify additional sources of evidence. This was subsequently submitted to the UK's Research Excellence Framework in 2014 (for summative evaluation by a panel of disciplinary and user experts, the results of which were withheld from case study authors).

\section{Results}

Phase 1 results: Application of social network analysis to understand impact of research on peatland and climate policy in Scotland

Stakeholders were asked to discuss a research finding of relevance to the management of Scottish peatlands. No prompts were given regarding topics or themes. The regularity with which a particular research topic was mentioned was considered one indicator of its impact. The information pathways for peatlands research reported by respondents are shown in a social network diagram in Figure 2. The pathways illustrate how information about research findings was sourced and disseminated through a network of stakeholders concerned with the Scottish uplands. Nodes in the network represent sources of, or targets for, information related to specific research findings. Nodes included individuals, organisations, partnership organisations and publications. Ties between nodes (Figure 2) represent the total number of instances that information exchange between nodes took place in relation to peatlands and climate change research. Qualitative responses from stakeholders revealed that there was a high degree of consensus among respondents from across the policy network (research, policy and practice) on the nature of the research findings discussed. At the most simplistic, respondents stated that they believed the science to have concluded that peatlands store large amounts of carbon. Some went on to discuss the value of carbon sequestration in peatlands for climate regulation. Others elaborated to include management recommendations including the need to preferentially restore eroded bogs and to avoid land management practices that damage and expose peat. Some responses highlighted gaps in the research, for example: "the precise nature of the extent and condition of the stock is unknown (rather little known about peat depth and density). The precise impact of management (e.g. managed moorland burning) on the nature of the underlying carbon store is also poorly understood" (Interest organization/NGO respondent, 2011).

\section{[insert Figure 2 here]}

The striking observation about the network above is the prominent role that certain interest organisations have in the information exchange network and their strong links with government agencies. These organisations represent interests in conservation and land management and some have a strong lobbying voice and are therefore influential in shaping pathways from research to policy and practice. The most well connected node represents the Royal Society for the Protection for Birds (RSPB), a large conservation organisation. Land management interest organizations tend to represent land managers and have strong links with private managers. In this case private managers predominantly exchanged information with land management interest organisations. However, there are also relatively isolated land managers who rely on media and there were generally very few interactions between land managers and research institutes. The other structural characteristic of note in the figure above is that research institutes such as universities had relatively weak ties in the network either with each other or with other types of organisation. Scientists at academic institutes and academic journal articles were mentioned as information sources but not consistently. 
A key information pathway was a review of peatlands and carbon commissioned by RSPB, with many stakeholders being aware of this study. There was also frequent mention of the International Union for the Conservation of Nature's (IUCN) UK Peatland Programme, which is overseen by a board consisting of environmental bodies (including RSPB), Government departments and agencies, prominent researchers and business land management representative bodies. Overall, each group of organisations (denoted by the boxes in Figure 2) had information exchange pathways with most other groups, and information flows were typically two-way at this level, even if not all nodes in a group were a regular contributor to these pathways. Other than interest organisations, the most connected group was partnership organsiations, like the IUCN UK Peatland Programme and the Scottish Government's Centre of Expertise, ClimateXChange (described in greater detail in the next section). It is clear that interest organisations (in particular) and partnership organisations (to a lesser extent) were functioning as key hubs of information, with strong input to government agencies and Scottish Government at the time of the survey. The fact that research institutes and scientific publications are playing a relatively marginal role in the research information pathways indicate possible weakness in the network. Dependence on interest organizations as main information sources may reduce awareness of research findings that are potentially important for informing climate change policy.

This SNA illustrates visually a key point in the process where a range of stakeholders recognized the results of a body of research and the wider meaning of those results in terms of opportunities (improved peatland management) and challenges (the needs for further science to build knowledge about how to develop policy and manage peatlands for improved carbon sequestration). The SNA shows that the isolation of those affiliated with research institutes was a weakness of the social network despite the wide recognition by stakeholders of a strong research evidence base.

To better understand this weakness, the qualitative part of the SNA interviews sought to understand perceived barriers to the use of research evidence in the policy network, and how these might be overcome. Two key themes emerged from the analysis of this data: ideological fracturing of the evidence base, and the need for more partnership working. In the rest of this section and the following section, paragraph headings denote the themes that emerged from the qualitative data analysis.

IDEOLOGICAL FRACTURING OF EVIDENCE: Respondents expressed concerns about a fracturing of the evidence-base, as a result of the ideological selectivity of interest groups and/or policy-makers. For example, some respondents explained how scientific evidence is used selectively to reinforce exisiting view-points within the policy network. As one Scottish Government policy-maker described it, "if they don't want to hear it, [they] just exclude it from their thinking" (Scottish Government interview respondent, 2013). The dominance of interest organisations with specific agendas in the information pathways may exacerbate the view that many individuals and organisations only hear part of the story from actors whom they regard as 'trusted' sources. As Marmot observes that "scientific findings do not fall on blank minds that get made up as a result. Science engages with busy minds that have strong views about how things are and ought to be" (Marmot 2004:906).

NEED FOR MORE PARTNERSHIP WORKING: Despite the apparent connectivity of the policy network (Figure 2), the need for improved partnerships and collaboration was a key theme that emerged from the analysis of interview transcripts. Building on this recognition, an initiative was underway to develop a knowledge hub that could more systematically and comprehensively generate and share evidence on climate change relevant to Scottish Government policy. 
"We're developing [for] peatlands, a research hub where we bring the main researchers together on peatland restoration where the researchers talk to the land managers as well as the policy advisors. If you can have that sort of hub, then you can be very effective but unless you have that sort of forum, it's very, very difficult." (Government agency interview respondent, 2010)

"I think bringing together teams of people to work on specific projects that have a clear start, a clear purpose and a clear end, I think is one of the best ways of breaking down barriers. So that they have a shared responsibility for delivering something" (Interest organization/NGO interview respondent, 2010)

The "hub" described by the former speaker, and the ideas expressed by the latter speaker, became ClimateXChange (CXC), which became the focus for interviews reported in the next section.

\section{Phase 2 results: Interview findings on knowledge exchange in Scottish climate policy}

ClimateXChange (CXC) is the pre-eminent science-policy interface for Scottish Government on issues linked to peatlands and climate change. Established in 2011 by the Scottish Government department for Rural Environmental Science and Analytical Services (RESAS) CXC is one of three 'Centres for Expertise' for key environmental policy areas of climate change, water and animal disease. CXC represents a new model for evidence-based policy, which aims to get the best possible evidence into policy fast. One mechanism within CXC is a 'call down service' for the Scottish Government in which a policy maker can: "pick up the phone and say 'help"' (CXC respondent, 2013). The CXC secretariat will then meet with the policy team, work out what evidence they need, and then source a team of researchers to produce a tailored policy briefing. Interviews conducted two years after the phase 1 interviews with CXC and Scottish policy makers, suggest that the following factors affect knowledge uptake:

TIMING IS CRITICAL: The timing of research provision is critical to ensuring evidence and expertise is targeted effectively at relevant points in the policy cycle. Timing was stressed during interviews with the CXC secretariat and directorate and featured strongly in CXC's 'policy awareness workshops' (held during 2012-13) to train scientists in undertaking policy responsive work.. Here the challenge was helping researchers to understand that "if they miss a policy deadline, that's it for five years, they're not going to have any impact" (CXC interview respondent, 2013). Timing is also not only about meeting briefing and consultation deadlines, but also about recognising that policy agendas are set in manifesto promises (Scottish Government interview respondent, 2014). Many NGOs were therefore focused on influencing manifesto writers for the next elections (NGO interview respondent, 2013).

PULLING EVIDENCE INTO POLICY: Research findings need to be relevant to the current policy challenge. Attaining policy relevance is about more than ensuring research finding speak in a timely manner to a given policy topic, but is also achieved through resonating with (or, at most modifying) current policy priorities (Machen forthcoming 2018). Research impact is easiest to achieve where it is pulled into policy as and when it is needed, in ways that are seen as useful within current policy frameworks. This pull model of science-policy interaction (exemplified by CXC's Call Down Service) is increasingly being complimented by a focus on co-production in which there is growing emphasis on policy and research teams working together from the outset to construct knowledge that has salience for policy requirements. 
THE IMPORTANCE OF SOCIAL NETWORKS IN EVIDENCE ACCESS AND USE: FlowS of scientific knowledge relied on social connections - between scientific teams, between policy teams, and between science and policy communities. First, as well as formal organisational networks, knowledge flows relies on interpersonal networks with key individuals (within CXC, RESAS and Scottish Government) appearing particularly important in connecting and lubricating the flows of research. Where many scientific researchers expressed frustration about the disruptive effect of civil service turnover on the continuity and operation of knowledge networks CXC provided a single point of stability. In addition, CXC was able to use staff affiliations with more than one institution or social network to share knowledge (and skills) between organisations that otherwise might not have been shared (Machen 2016). Second, where some research scientists described little previous professional connection with the Scottish Government it was suggested: "ClimateXChange is changing that" (CXC interview respondent, 2013). CXC sought to increase the interaction between scientists and policy makers through secondments, workshops and encouraging scientists to identify and get to know their relevant policy teams within Scottish Government. This was considered crucial in both prompting call down service requests from policy teams, and ensuring scientists knew their audience. Interviews with RESAS suggest that policy teams engage directly with science being produced by researchers in Scotland only "If they know right people, if they have established the contacts" (Scottish Government interview respondent, 2013).

THE ROLE OF TRUST: Two-way, long-term trusting relationships recurrently emerged as critical to overcoming barriers between policy-makers and scientists. As one CXC member of staff described: "this whole notion of knowledge exchange to me is all about person to person trust ... ifyou trust the person opposite when they say something you'll listen, if you don't trust them, or you don't know them particularly well, it's just another bit of paper and you've got lots of bits of paper, so an awful lot of what we're trying to do is actually build trust" (CXC interview respondent, 2013). Significant time and energy is spent building these relations of trust. For example, an interviewee from the CXC Secretariat explained, "we go and sit down with the policy team and work out what evidence they could do with, and how we can help...[we've] been to all the different policy team leads across the Scottish Government ... pretty much every single one of them this year" (CXC interview respondent, 2013). In building this trust among policy teams, CXC are building organisational credibility - "trying to build credibility and reassurance that we're not a bunch of another bunch of academics pushing academic work, we're actually there to work out what the problem is and see if we can find a solution" (CXC interview respondent, 2013). This responsiveness (in appearing not to have an agenda) was a recurrent marker of trust.

\section{Phase 3 results: Narrative impact evaluation}

Broadly speaking, two bodies of research played a role in the development of Scottish Government policy on peatlands and climate change. The first body of research was UKwide, and synthesized a broad range of research from different academic disciplines over at least ten years to demonstrate that over appropriate timeframes (e.g. 30-100 year contracts) good practice peatland restoration can deliver significant climate change mitigation benefits. This body of work, first synthesized by the IUCN Commission of Inquiry on Peatlands (Bain et al., 2011), and most recently summarized by Reed et al. (2017), was cited by respondents in each of the two empirical data collection phases. This body of work subsequently underpinned the development of the Peatland Code Version 1.1, which was published in 2015, and was part of a body of work informing the development of a UK Peatland Strategy by IUCN UK Peatland Programme in 2017, which includes a Scottish Peatland Action Plan. 
The second body of research adapted international research findings on peatlands and climate change to the specific policy needs of Scottish Government, and was led by CXC. Building on international research evidence, CXC developed a peatland restoration decision support tool (WISE Peatland Choices) and provided three policy briefs in relation to Scottish Government via "call-down requests". CXC guidance on Greenhouse Gas emissions from restored sites provided clear evidence that the long-term benefits of peatland restoration outweighed any short-term negative climate impacts from shortlived methane emissions and was used by the Scottish Government's climate change policy team as oral evidence presented to the Report on Policies and Procedures (the mechanism for implementing the Climate Change Act in Scotland) and a Rural Affairs, Climate Change and Environment (RACCE) Committee meeting on the benefits of peatland restoration on $6^{\text {th }}$ Febr 2013.

As is typically the case with impact evaluation, it is difficult to disentangle the influence of these two bodies of research in shaping policy and action. There is however a direct link between the UK Peatland Strategy which was co-developed by the IUCN UK Peatland Programme (and linked to Scotland's Peatland Action Plan) and a 2013 letter signed by all four UK country Ministers (including the then Scottish Environment Minister) to the IUCN UK Peatland Programme, that sets out a framework for action, including co-operation and co-ordinated action to support the development of a Peatland Code to operate across the $\mathrm{UK}^{4}$, an intention that was re-iterated in the UK Government's National Adaptation Plan in July 20135, citing the first body of research.

Three indicators help build the case for research impact directly arising from second body of research. First, CXC researchers involved in the work highlighted the specific role that CXC's interventions had played in reducing uncertainty of estimates during the RACCE Committee meeting (above) and the author of the CXC policy briefs suggested that the contention within the policy briefs that peatland restoration could represent as much as $15-40 \%$ of Scottish transport figures until 2020 was particularly important in stimulating policy action. Second, there are numerous testimonials to the value of CXC's work by Scottish Government civil servants. Interviews with members of the policy community in Scottish Government suggested that the evidence presented to these committees was instrumental in the allocation of $£ 1.7 \mathrm{~m}$, subsequently rising to $£ 15 \mathrm{~m}$ for peatland restoration between 2012-16 as Peatland Action and during wider interviews with RESAS, CXC's three peatland policy briefings were spontaneously highlighted as examples of best practice in science-policy interaction, with knowledge particularly well received by the Scottish Government's Natural Assets and 186 Flooding Division, and well used in the RPP2 (Scottish Government interview respondant, 2013). Thirdly, the research can be directly traced to policy action. As part of a body of evidence, CXC's work contributed the foundations for a proposal in the second Report on Policies and Priorities in 2013 that 21,000 ha of peatlands per year should be restored in the period to 2027, and researchers from James Hutton Institute were subsequently tasked to help draft the national Peatland Plan, which was put out to consultation in 2014.

\footnotetext{
${ }^{4}$ http://www.iucn-uk-peatlandprogramme.org/sites/all/files/20130205 Joint DA letter to IUCN.pdf

${ }^{5}$ https://www.gov.uk/government/uploads/system/uploads/attachment_data/file/ 209866/pb13942-nap-20130701.pdf
} 


\section{Discussion}

In this paper, we have proposed and tested a method for planning and facilitating research impact, using a logic model combined with a modified approach to stakeholder analysis that is designed to work with both publics and stakeholders to identify and prioritise hard-to-reach groups. The approach was tested through a series of linked research projects between 2005-2014 and was integrated into a research impact training programme from 2013-present. It has since been widely used across the UK research community. Here, we empirically evaluate and discuss the utility of the method and draw out further insights from this case study based evaluation.

\section{Methods for planning and facilitating impact}

Although the impact plan in the logic model (Table 3) focused on UK-wide rather than just Scottish policy impacts, evidence from our Scottish case study research shows that significant and far-reaching policy impacts arose from the work, broadly in line with the plan proposed in the logic model. However, in addition to anticipated research impacts (envisaged in the logic model at the outset), an additional body of research was generated in Scotland by the Scottish Government's Centre of Expertise, ClimateXChange, which proved pivotal in securing a number of important additional policy impacts. Although this country-specific research built explicitly on many of the papers from the national and international literature that were originally envisaged by the research team, many specific research applications and policy impacts in Scotland were not planned for at the outset. Indirect, unanticipated pathways to policy impact, such as these, are commonly found in the study of science-policy processes (e.g. Young et al., 2002). Indeed, Bowen and Zwi (2005) argue that there is scope for both direct and indirect influence on policy at three stages in the policy process, during the sourcing, use and implementation of evidence. In this case, much of the additional evidence was sourced from ClimateXChange to support the use and implementation of international evidence (much of which arose from the first planned-for, UK body of evidence) in the Scottish context.

Although it is not possible to prove causality between the first (planned-for, UK-wide) body of research and impact, and the second (not planned-for, Scotland focused) body of work, there are some links that can be established. For example, there was significant overlap between the actors in the policy network identified as being important in our phase 1 Social Network Analysis (in terms of their connectivity and network position) who were using the first body of work, who we found (in phase 2 of our research) were pivotal in the development and use of the second body of work in Scottish policy.

By tracing the pathway from research to policy impacts in depth (phase 3 of our research), we are able to demonstrate the utility of the proposed approach for planning and facilitating impact, but caution against its use as a prescriptive or predictive tool. The combination of logic model and public/stakeholder analysis enables structured planning of activities that are matched to the interests of specific stakeholders or publics, and so are more likely to meet their needs and deliver impacts that can be clearly evidenced. The integration of public/stakeholder analysis is essential to provide a systematic assessment of the likely needs and interests of different stakeholders and publics, reducing the likelihood of overlooking marginalized and hard-to-reach groups. 


\section{Methods for evaluating policy impacts from research}

To further evaluate the impacts arising from the use of this approach, we proposed and tested a novel combination of methods for evaluating impact, based on a narrative "impact case study" review, informed by in-depth interviews and an adapted form of social network analysis that was designed to capture flows of knowledge from research into policy through science-policy networks.

Impact evaluation methods from the realms of evidence-based policy and researchinformed international development typically follow a hierarchy of methods, with randomised controlled trials, followed by quasi-experiments, mixed methods and qualitative methods (e.g. Gertler et al. 2011; HM Treasury 2011; USAID 2011). Implicit in this hierarchy is the idea that quantitative measures are superior to qualitative approaches, and the task of evaluation is to attribute a cause (in this case linked to research) to an effect (in this case impact). However, it is increasingly clear that the relationship between research and impact is far more indirect, non-linear and complex than these evaluation frameworks typically allow (UNEG 2013; Befani et al., 2014; Reed, 2018). As a result, many evaluations of research impact fail to capture the multifaceted and long-term benefits arising from research, and so offer few lessons to enhance future practice (Cartwright and Hardie 2012; Woolcock 2013; Befani et al., 2014). In response to this, there is now a rapidly growing range of research impact evaluation methods available. Reed (2018) has categorized these as: 1) theory or logic driven; 2) experimental; 3) statistical; 4) contribution and pathway analysis; 5) case-based and narrative analysis; 6) participatory; 7) evidence synthesis; and 8) arts-based. In this study, we drew on methods from across these types of research impact evaluation, integrating a new logic model with contribution and pathway analysis (using SNA in phase 1 of the research) and case-based and narrative analysis (using interviews and narrative review in phases 2 and 3).

The role of SNA for understanding governance structures in natural resource management has been well-studied (Crona and Hubacek 2010; Salpeteur et al., 2017) and SNA has been used to study knowledge brokerage and bridging links (e.g. boundary organisations) in a number of science-policy networks (e.g. Cvitanovic et al. (2017) in Australia and Gama et al. (2017) in Portugal)). SNA has been used to assess information exchange in public health research where it has provided insights into how policy makers source information and evidence (Oliver et al. 2017). As in our study, Oliver et al. found that academics, while part of the network, were not central to knowledge exchange. We show that SNA can provide a quantitative and visual description of the social dynamics of knowledge exchange, tracing policy impacts back to original research outputs to provide a robust case for the contribution of research to policy. If research impacts are by definition underpinned by processes of knowledge exchange, as Reed (2018) argues, understanding these patterns can inform the process of understanding and enhancing research impact. As such, SNA has considerable potential as part of a set of tools to evaluate research impact, as evidenced in this paper.

Combined with publics/stakeholder analysis, categorising individuals and organisations according to their degree of interest and influence in a particular issue, SNA can be used to track the actual impact of knowledge from research in terms of the extent to which it is exchanged, used and adapted by different groups. For example, understanding knowledge flows in a social network and the extent to which these are influenced by different actors, can aid the planning of research initiatives, so that strong research collaborations are forged at the right time in a policy cycle. Identifying parts of the network where information flow is weak or impeded can highlight the need for collaborations and trust building. 
The conception of science to policy pathways as linear and unidirectional has been largely dispelled in the literature (Young et al., 2014), yet there are few methods available to represent the complexity of pathways to policy impact, which can aid the design of effective knowledge exchange interventions. Social network analysis (SNA) is a method that captures the complex and multidirectional nature of interactions between individuals and groups/organisations. It has the capacity to evaluate the importance and impact of two-way interaction, frequency of interaction and the role of certain individuals and organisation as 'bridges' between others who might otherwise be only weakly linked, or who do not communicate at all. SNA can also illustrate the effects of conflict or a lack of trust on the interactions among stakeholder groups. Using SNA and qualitative methods together to understand the perspectives of the stakeholder groups involved can illustrate where knowledge flows are strongest and where there are barriers or pathways that could be strengthened to build up trust and facilitate the exchange and collaborative development of knowledge.

The social network produced shows the information pathways that have contributed to an individuals' awareness and perception of specific information or evidence and the importance of social ties for generating research impact. The SNA for this study represents a snapshot in time and is not a full analysis of the social positioning of actors in relation to issues of climate change.Carrying out a full SNA to understand the broader social dynamics of stakeholders would have allowed greater interpretation of the observed knowledge exchange pathways. However we suggest that as part of the wider set of tools described in this paper, providing researchers with a focused method to track the exchange and use of specific research findings will help them identify ways to enhance impact, through understanding contextual social dynamics that exist in policy networks. The iterative nature of both the research process and shifting knowledge and perspectives on research outputs means that the network dynamics constantly change as does the information that is exchanged. This approach did not account for how individuals' values and prior knowledge contribute to how research evidence is received, perceived and passed on to others, but such data may be collected as node attributes to better understand the role of such variables.

The method used was limited in determining the precise pathways by which information was transmitted as data on information exchange could not be gathered at each transmission step or node. Collecting SNA data from individuals is labour-intensive and science to policy networks are not easily defined and bounded. However, our method was effective in measuring the relative influence of different individuals, organisations and other information sources on the awareness and understanding of research in science to policy networks and as such may be used to design more effective pathways to policy impact.

\section{The role of trust in pathways to policy impacts}

Factors that affect the influence of science-policy interfaces include the credibility, salience, legitimacy and ultimately trust in the knowledge production process and how its outputs are shared (Cash et al. 2003; Lacey et al., 2018). Trust in how knowledge is produced and shared depends on the nature of the expectations between parties, the willingness of parties to accept risk or vulnerability, levels of dependence or interdependence between parties and the subjective perceptions of the person, group or 
organisation who has to trust (Stevens et al., 2015; Lacey et al., 2018). These perceptions are typically shaped through social interaction, but may also be influenced by contextual factors, such as personal and institutional reputations and values inferred from historic interactions (Saunders et al., 2010). For example, working in the context of land use and conservation policy, Reid et al. (2016) emphasised the role of individual values and character in establishing and building trust, and de Vries et al. (2014) emphasised the temporal dynamics of trust relationships as both the individual and organisational level. While trust is identified as playing a positive role in science-policy dialogue across much of the literature, there is also evidence that "too much trust" can lead to trust can also lead to a lack of critical interpretation of evidence ('blind faith') limiting the ability to integrate other ideas, identify alternative options or re-appraise a course of action (Stevens et al., 2015; Stern and Baird, 2015).

Science-policy interfaces (including individual science-policy mediators, collaborative and participatory mediation processes and boundary organisations) are designed to engender trust in both the process and outputs of knowledge production (van Enst et al., 2014). There is a growing body of evidence explaining how these interfaces can influence the uptake of research in policy. For example, Ulibarri (2018) showed research developed collaboratively with members of the policy community was more likely to be used than research developed through consultation, because policy-makers understood the research and its limitations, trusted the research and the researchers, and the research was perceived to be better designed because it directly took into account their knowledge and questions. Similarly, Sarkki et al., (2015) emphasise the importance of iteration in science-policy processes where repetition builds trust and mutual understanding, an important component of social learning. There is therefore a need to develop research to policy pathways where the processes of collaboration, iteration and social learning underpin good quality research outputs in a way that generates trust and credibility amongst the broader stakeholder community.

This is a challenge for the research community. While there can be a lack of trust towards the use of evidence by interest organisations perceived to be lobbying for particular policies (MacKenzie and O'Doherty, 2011), researchers must also consider the extent to which they have specific interests, and should therefore be treated as stakeholders (Burgess, 2014). Although researchers may be perceived as more neutral than interest groups, they may also be perceived as detached from policy demands and self-serving, creating mistrust (Scottish Government interview respondent, 2013). Trust in researchers who are perceived as distant and removed from the system of study can be particularly low, if they are unknown to the policy or practitioner community (Practitioner interview respondent, 2011). In our case study, individual researchers played a relatively marginal role in science to policy translation (as suggested by the position of research organisations in our SNA, Figure 2). Instead, and this paper has emphasised the way in which interest groups can play an important role in re-packaging scientific knowledge and working to gain traction for this knowledge within policy circles on behalf of scientific researchers. Here long-term inter-personal and interorganisational relationships of trust are central to the standing and voice that such organisations are able to command. A useful avenue for further research in tracing research impact could bring together an SNA driven assessment of knowledge flows with trust-maps (Krackhardt and Hanson, 1993) to further explore both these formal, and more informal inter-personal networks through which knowledge finds footholds into policy discourse. 
CXC essentially functions as a 'boundary organisation' (Guston, 1999), involving the participation of actors from both sides of the research-policy boundary, and staffed by professionals who serve a mediating role. As a boundary organization, CXC both connects and demarcates science to and from policy, ostensibly bringing science and policy closer together, but at the same time regulating how and when knowledge exchange/(co)production takes place, and who is involved in these research to policy pathways. In performing this role, CXC provides a single body to which policy makers can turn for advice, and a mechanism through which scientists and decision makers can interact, and build mutual understanding and trust.

While still in its early stages, CXC represents a new type of boundary organisation, one that is shaping a demand-led mode of policy interaction. This reconfigures the social dynamics of the relationship between knowledge producers and users - reshaping how and why knowledge is produced through both its translation and co-production practices. On one hand CXC changes the social dynamics within the social network in which it is situated, enabling and empowering researchers within the research institutes who may feel isolated to increase possibilities for achieving research impact by building familiarity, trusted relations and policy presence ${ }^{6}$. On the other hand, CXC's shift in the balance of power between producers and users means that the policy framing of the user gains greater weight in the shaping of environmental knowledge, which has implications for the politics of knowledge construction at the science-policy interface (Machen 2018, forthcoming). In following a co-production approach, CXC further deconstructs the binary distinction between producers and users of knowledge initiating instead a new mode of knowledge prosumer (Toffler 1980).

\section{Conclusion}

We have proposed and tested a comprehensive methodology based on an adapted logic model and a new approach public/stakeholder analysis that considers the relative interest, benefit and influence of stakeholders and publics in relation to research. When combined with social network analysis and qualitative interviews these methods can enable researchers and stakeholders to plan for, facilitate and evaluate research impact effectively. Our approach is based on understanding the complex social dynamics that tend to characterize science to policy pathways.

The social network analysis illustrated the structure of a relatively well-connected policy network, which was in the process of developing evidence communication pathways about peatlands and climate change. It highlighted the central position and influence of interest organisations in information pathways in contrast to the relative isolation of research institutes. Qualitative evidence supported the apparent need for a process that would allow researchers and policy makers to generate policy relevant evidence in a more collaborative and systematic way. Further qualitative interviews provided insights into how the observed social dynamics led to the development of a boundary organization and its subsequent role in generating impact from climate and peatlands science.

${ }^{6}$ Where working with interest organisations/NGOs would be another way to achieve this policy influence, this avenue could appear less palatable to those for whom the (well-refuted) scientific ideals of neutrality and impartiality remain dear. 
In addition to these empirical insights, we have made two methodological contributions: first proposing and testing methods for planning and facilitating pathways to policy impact from research; and second proposing and testing methods for evaluating pathways to policy impact that are able to capture the complex social dynamics of knowledge exchange in science-policy networks. Both methods provide researchers and other stakeholders with important opportunities for feedback and reflection that have the potential to increase the availability and effectiveness of evidence in the policymaking process.

Evidence from applying these new methods for planning facilitating and evaluating impact in the context of climate change in Scotland, shows that they can provide constructive feedback and evidence to researchers pursuing policy impacts from their work. Although the resources associated with replicating the full methodology including social network analysis and the qualitative analysis of semi-structured interviews may be more resource-intensive than many projects can afford, the impact planning template proposed in the second part of the paper can be rapidly and easily be used by researchers from any discipline. By identifying activity and impact indicators linked to impact goals, the proposed logic model can help researchers design an effective impact evaluation.

Across our combined methods, trust emerged as an important factor that mediated research impact. Boundary organizations and centrally positioned, well-trusted individuals, were crucial to the development of a trusted body of research in which policy-makers were sufficiently confident as the basis for policy. Crucially, the boundary organization that emerged during the course of the research, ClimateXChange, provided an open door and stable point of reference between the policy and research communities, fostering an increasingly co-productive approach to the commissioning, conduct and use of research. Social networks were crucial conduits for knowledge exchange, providing access to evidence and informing its interpretation and use. Social processes that recognize the importance of trust and invest in trust building were essential for achieving impact from research. By further recognizing and elucidating the social dynamics of knowledge exchange and impact, we emphasise the non-linear, indirect and "messy" nature of policy impacts from research, and yet argue that this dynamism can be evaluated, understood and planned for.

\section{Acknowledgements}

This research was funded by EU Framework 7 under the Ecocycles project, and draws on research funded by the Rural Economy and Land Use programme and ESRC funded Sustainable Uplands project, Durham Doctoral Studentship PhD research and a Scottish Government funded evaluation of their Strategic Research Portfolio. Thanks to Kathryn Oliver for insightful feedback as guest editor, which helped shape and significantly improve this paper and two anonymous reviewers.

\section{References}

Befani, B, Barnett, C, Stern, E, 2014, Introduction-Rethinking impact evaluation for 
development, IDS Bulletin 45, 1-5

Bowen, S, Zwi, AB, 2005, Pathways to "evidence-informed" policy and practice: a framework for action, PLoS medicine 2, p.e166

Brugha, R, Varvasovszky, Z, 2000, Stakeholder analysis: a review, Health policy and planning 15, 239-246

Burgess, MM, 2014, From 'trust us' to participatory governance: Deliberative publics and science policy, Public understanding of science $23,48-52$

Cairney, P, Oliver, K, 2017, Evidence-based policymaking is not like evidence-based medicine, so how far should you go to bridge the divide between evidence and policy? Health research policy and systems 15, 35

Cartwright, N, Hardie, J, 2012, Evidence-Based Policy: A Practical Guide to Doing It Better, Oxford: Oxford University Press

Cash, DW, Clark, WC, Alcock, F, Dickson, NM, Eckley, N, Guston, DH, Jäger, J, Mitchell, RB, 2003, Knowledge systems for sustainable development, Proceedings of the national academy of sciences 100, 8086-8091

Crona, B, Huback, K, 2010, The Right Connections: How do Social Networks Lubricate the Machinery of Natural Resource Governance. Ecology and Society 15, 18

Cvitanovic, C, Cunningham, R, Dowd, AM, Howden, SM, Putten, EI, 2017, Using Social Network Analysis to Monitor and Assess the Effectiveness of Knowledge Brokers at Connecting Scientists and Decision- Makers: An Australian case study, Environmental Policy and Governance 27, 256-269

de Vries, JR, Roodbol-Mekkes, P, Beunen, R, Lokhorst, AM, Aarts, N, 2014, Faking and forcing trust: the performance of trust and distrust in public policy, Land use policy $38,282-289$

Donaldson, T, Preston, L, 1995, The stakeholder theory of the modern corporation: concepts, evidence and implications, Academy of Management Review 20, 65-91.

Freeman, RE, 1984, Strategic management: a stakeholder approach, Boston, MA: Pitman.

Gama, R, Barros, C, Fernandes, R, 2017, Science Policy, R\&D and Knowledge in Portugal: an Application of Social Network Analysis, Journal of the Knowledge Economy https://doi.org/10.1007/s13132-017-0447-3

Gasper, D, 2000, Evaluating the 'logical framework approach' towards learning-oriented development evaluation, Public Administration and Development 20,17-28

Gertler, PJ, Martinez, S, Premand, P, Rawlings, LB, Vermeersch, CMJ, 2011, Impact Evaluation in Practice, Washington DC: World Bank

Grimble, R, Chan, MK, 1995, Stakeholder analysis for natural resource management in developing countries. Natural Resources Forum 19, 113-124

Guston, DH, 1999, Stabilizing the boundary between US politics and science: The role of the Office of Technology Transfer as a boundary organization, Social Studies of Science 29, 87-112

Heclo, H, 1978, Issue networks and the executive establishment. Public Administration 
Concepts and Cases 413, 46-57

HM Treasury, 2011, The Magenta Book: Guidance for Evaluation, London: HM Treasury

Julian, DA, 1997, The utilization of the logic model as a system level planning and evaluation device, Evaluation and Program Planning 20, 251-257

Krackhardt, D, Hanson, JR, 1993, Informal networks: the company behind the chart, Harvard Business Review 71, 104-111

Lewis, JM, 2006, Being around and knowing the players: networks of influence in health policy, Social Science \& Medicine 62, 2125-2136

Machen, KRM, 2016, Re-Working Boundaries: Values And Legitimation At The Climate Science-Policy Interface, Unpublished Doctoral Thesis, Durham University

Machen, R forthcoming 2018, Towards A Critical Politics Of Translation: (Re) Producing Hegemonic Climate Governance, Environment and Planning E: Nature and Space

MacKenzie, MK, O’Doherty, KC, 2011, Deliberating future issues: Minipublics and salmon genomics, Journal of Public Deliberation 7(1), Art. 5.

Marmot, MG, 2004, Evidence based policy or policy based evidence? Willingness to take action influences the view of the evidence - look at alcohol. British Medical Journal $328,906-907)$

Meagher, LR, Martin, U, 2017, Slightly dirty maths: The richly textured mechanisms of impact, Research Evaluation 26,15-27

Mitchell, RK, Agle, BR, Wood, DJ, 1997, Toward a theory of stakeholder identifi- cation and salience: defining the principle of who and what really counts, Academy of Management Review 22, 853-886

Oliver, KA, de Vocht, F, Money, A, Everett, M, 2017, Identifying public health policymakers ${ }^{1}$ sources of information: comparing survey and network analyses, European Journal of Public Health 27, 118-123

Reed, MS, Graves, A, Dandy, N, Posthumus, H, Hubacek, K, Morris, J, Prell, C, Quinn, CH, Stringer, LC, 2009, Who's in and why? Stakeholder analysis as a prerequisite for sustainable natural resource management, Journal of Environmental Management 90, 1933-1949

Reed, MS, Evely, AC, Cundill, G, Fazey, I, Glass, J, Laing, A, Newig, J, Parrish, B, Prell, C, Raymond, CM, Stringer, LC, 2010, What is social learning? Ecology \& Society 15 (4), r1.

Reed, MS, Curzon, R, 2015, Stakeholder mapping for the governance of biosecurity: a literature review, Journal of Integrative Environmental Sciences 12, 15-38

Reed, MS, Meagher, L 2018, Environment and sustainability. In: Boaz, A, Davies, H, Fraser, A, Nutley, S, (eds.) What Works Now? Evidence-based policy and practice revisited, The Policy Press: Bristol

Reed, MS, Allen, K, Dougill, AJ, Evans, K, Stead, SM, Stringer, LC, Twyman, C, Dunn, H, Smith, C, Rowecroft, P, Smith, S, Atlee, AC, Scott, AS, Smyth, MA, Kenter, J, Whittingham, MJ, 2017, A Place-Based Approach to Payments for Ecosystem 
Services, Global Environmental Change 43, 92-106

Reed, MS, 2018, The Research Impact Handbook. $2^{\text {nd }}$ Edition, Fast Track Impact

Reid, RS, Nkedianye, D, Said, MY, Kaelo, D, Neselle, M, Makui, O, Onetu, L, Kiruswa, S, Kamuaro, NO, Kristjanson, P, Ogutu, J, 2016, Evolution of models to support community and policy action with science: Balancing pastoral livelihoods and wildlife conservation in savannas of East Africa. Proceedings of the National Academy of Sciences 113, 4579-4584

Rhodes, RA, 1992. Beyond Westminster and Whitehall: The sub-central governments of Britain. London: Routledge

Rush, B, Ogborne, A, 1991, Program logic models: expanding their role and structure for program planning and evaluation. The Canadian Journal of Program Evaluation 6, 95

Salpeteur, M, Calvet-Mir, L, Diaz-Reviriego, I, Reyes-García, V, 2017, Networking the environment: social network analysis in environmental management and local ecological knowledge studies, Ecology and Society 22(1), 41

Saunders, MNK, Skinner, D, Dietz, G, Gillespie, N, Lewicki, RJ, 2010, Organizational Trust: A Cultural Perspective. Cambridge University Press, Cambridge

Sarkki, S, Tinch, R, Niemela, J, Heink, U, Waylen, K, Timaeus, J, Young, J, Watt, A, Neßho, C, Hove, S, Van Den, 2015, Adding "iterativity" to the credibility, relevance, legitimacy: A novel scheme to highlight dynamic aspects of science - policy interfaces, Environmental Science \& Policy 54, 505-512

Stern, MJ., Baird, TD, 2015, Trust ecology and the resilience of natural resource management institutions, Ecology \& Society 20 (2), 14

Stevens, M, MacDue, JP, Helper, S, 2015, Reorienting and recalibrating interorganizational relationships: strategies for achieving optimal trust, Organizational Studies 36, 1237-1264

Strauss, A, Corbin, J, 1994, Grounded theory methodology, Handbook of qualitative research $17,273-85$

Toffler, A, 1980, The Third Wavem London: Bantam.

Ulibarri, N, 2018, Collaborative model development increases trust in and use of scientific information in environmental decision-making. Environmental Science \& Policy 82, 136-142

UNEG, 2013, Impact Evaluation in UN Agency Evaluation Systems: Guidance on Selection, Planning and Management, New York: United Nations Evaluation Group

USAID, 2011, USAID Evaluation Policy: Evaluation, Learning from Experience, Washington DC: United States Agency for International Development

Valente, TW, Pumpuang, P, 2007, Identifying opinion leaders to promote behavior change, Health Education \& Behavior 34(6), 881-896

Van Enst, WI, Driessen, PP, Runhaar, HA, 2014, Towards productive science-policy interfaces: a research agenda, Journal of Environmental Assessment Policy and Management 16, 1450007 
Woolcock, M, 2013, Using Case Studies to Explore the External Validity of "Complex" Development Interventions Evaluation 19, 229-48

Young, K, Ashby, D, Boaz, A, Grayson, L, 2002, Social science and the evidence-based policy movement, Social Policy and Society 1, 215-224

Young, JC, Waylen, KA, Sarkki, S, Albon, S, Bainbridge, I, Balian, E, Davidson, J, Edwards, D, Fairley, R, Margerison, C, McCracken, D, 2014, Improving the science-policy dialogue to meet the challenges of biodiversity conservation: having conversations rather than talking at one-another, Biodiversity and Conservation 23, 387-404

Young, JC, Searle, K, Butler, A, Simmons, P, Watt, AD, Jordan, A, 2016, The role of trust in the resolution of conservation conflicts, Biological Conservation195, 196-202. 